\title{
Multiple Autoimmune Syndrome: A Study of 25 Senegalese Cases
}

\author{
Moustapha Niasse ${ }^{1 *}$, Baïdy Sy Kane ${ }^{2}$, Alain Dimitri Walah Mabom1, Carole Makougang1, \\ Moudine Dézoumbé1, Yetna Tcheindah¹, Diouf Coumba', Saer Diadié3 ${ }^{3}$, Saïdou Diallo' \\ ${ }^{1}$ Department of Rheumatology, Cheikh Anta Diop University, Aristide Le Dantec Hospital, Dakar, Senegal \\ ${ }^{2}$ Department of Internal Medicine, Cheikh Anta Diop University, Aristide Le Dantec Hospital, Dakar, Senegal \\ ${ }^{3}$ Department of Dermatology, Cheikh Anta Diop University, Aristide Le Dantec Hospital, Dakar, Senegal \\ Email: *moustaphaniasse4@yahoo.fr
}

How to cite this paper: Niasse, M., Kane, B.S., Mabom, A.D.W., Makougang, C., Dézoumbé, M., Tcheindah, Y., Coumba, D., Diadié, S. and Diallo, S. (2020) Multiple Autoimmune Syndrome: A Study of 25 Senegalese Cases. Open Journal of Rheumatology and Autoimmune Diseases, 10, 14-23. https://doi.org/10.4236/ojra.2020.101003

Received: January 21, 2020

Accepted: February 16, 2020

Published: February 19, 2020

Copyright $\odot 2020$ by author(s) and Scientific Research Publishing Inc. This work is licensed under the Creative Commons Attribution International License (CC BY 4.0).

http://creativecommons.org/licenses/by/4.0/

\begin{abstract}
Introduction: Multiple autoimmune syndrome is rarely described in the African literature. We report 25 cases. Patients and Method: A Retrospective, descriptive study was carried out in the Rheumatology Department of Aristide Le Dantec University Hospital in Dakar from 2013 to September 2019. Patients with at least 3 distinct autoimmune diseases were included. Results: Twenty-five cases of multiple autoimmune syndrome were collected in 23 women and 2 men, with a mean age of 42.4 years (extremes: 24 and 67 years). The mode of discovery of the disease was a connective tissue disease in 19 cases (76\%) and an organ-specific autoimmune disease in 6 cases. According to Humbert and Dupond's classification, 18 patients (72\%) had both type 2 and type 3 criteria. An isolated type 2 was noted in 5 cases (20\%) and an isolated type 3 in 1 case (4\%). One case (4\%) was unclassifiable. The evolution under treatment was marked by remission in $84 \%$ of cases. Conclusion: Multiple autoimmune syndromes account for $5.66 \%$ of the autoimmune diseases in our study. They predominate in young women with a mean age of 42.4 years. Not all entities were classifiable by the Humbert and Dupond's classification. The evolution under treatment was marked by remission in $84 \%$ of cases.
\end{abstract}

\section{Keywords}

Autoimmune Disease, Multiple Autoimmune Disease, Polyautoimmunity

\section{Introduction}

Autoimmune diseases represent a heterogeneous group of conditions. However, they can be divided into two groups. The first group includes single organ spe- 
cific autoimmune diseases, where the antigen is found in only one organ (vitiligo, pernicious anemia, Graves' disease...). In the second group, we have systemic autoimmune diseases, also called connective tissue diseases, where the antigen is located in several organs [rheumatoid arthritis (RA), Sjögren's syndrome (SS), systemic lupus erythematosus (SLE), systemic scleroderma (SSC)...].

Autoimmune diseases, whether single organ specific or systemic, can be associated [1] [2]. Thus, the association of at least three autoimmune diseases was individualized in 1988 by Humbert and Dupont as multiple autoimmune syndrome (MAS) [1]. Although $25 \%$ - 30\% of autoimmune diseases are thought to progress to polyautoimmunity [2], multiple autoimmune syndrome is more commonly reported in the Western literature [2]-[11]. In Southern Africa [12] [13], and in North Africa [14] [15] [16] [17], the disease was described as isolated observations or short series [12]-[17].

The aim of this study is to describe the epidemiological, diagnostic and evolutive data under treatment of patients with multiple autoimmune syndrome in a rheumatology department in Dakar.

\section{Patients and Method}

This study was a retrospective, descriptive study carried out in the Rheumatology Department of Aristide Le Dantec University Hospital in Dakar from 1st January and 30th September 2019. Patients with at least 3 distinct autoimmune diseases were included. We excluded all incomplete observations that did not allow a reliable exploitation of data. The informed consent of all the patients was required.

The diagnosis of constitutive tissue diseases was established, on epidemiological, clinical, paraclinical backgrounds and in accordance with their international classification criteria: RA (American College of Rheumatology and European League against Rheumatism 2010), SS (American-European consensus criteria of 2002), SLE (Systemic Lupus International Collaborating Clinics 2012), and SSC (American College of Rheumatology and European League against Rheumatism 2010).

For the single organ specific autoimmune diseases:

- Graves' disease was diagnosed with thyrotoxicosis syndrome and specific signs of the disease (vascular goiter, exophthalmos), decrease of thyroid stimulating hormone (TSH), increase of free T4 (FT4) and the positivity of anti-TSH receptors antibodies;

- Diagnosis of Hashimoto's disease was based on the presence of bradycardia, goiter, myxedematous syndrome, increase of TSH, decrease of FT4 and positivity of antithyroid peroxidase antibodies and anti-thyroglobulin antibodies;

- Perniciousanemia was characterized by a neurological and anemic syndrome, vitamin B12 deficiency, atrophic fundic gastritis and the existence of antibodies against intrinsic factor receptors;

- The diagnosis of vitiligo was retained on clinical examination after a dermatological opinion. 
For each observation, the following data had specified:

- Epidemiological data: age, gender;

- The diagnostic data: the autoimmune diseases which constitute the MAS, the type of MAS, according to the classification of Humbert and Dupont (Table 1);

- The evolution under treatment.

Data collection and analysis was performed using excel 2013 and SPSS version 20.0 .

\section{Results}

A total of 7000 patients were followed up for rheumatic pathology. Among these patients, 441 had an autoimmune disease (6.30\% of all rheumatic diseases), including 330 isolated autoimmune diseases (74.82\% of autoimmune diseases), 86 combinations of 2 autoimmune diseases (19.50\% of autoimmune diseases) and 25 MAS (5.66\% of autoimmune diseases). The association of two or more autoimmune diseases was $25.18 \%$. These MAS were found in 23 women and 2 men, with a mean age of 42.4 years (extremes: 24 and 67 years). A family background of autoimmune disease was found in 21 cases (84\%). The average time to the diagnosis was 2.52 years (extremes: 1 year and 10 years). The mode of discovery of MAS was connective tissue disease in 19 cases (76\%) and ingle organ specific autoimmune in 6 cases (24\%) (Table 2).

MAS associated 4 autoimmune diseases in 3 cases (12\%) and 3 autoimmune diseases in 22 cases ( $88 \%)$. The autoimmune diseases constituting the MAS were dominated by SS, found in 23 cases (92\%), followed by RA, found in 15 cases (60\%) (Figure 1). The most frequent association was the trio: SS + SLE + SSC ( $28 \%$ of cases), followed by the trio: RA + SS + Perniciousanemia (20\% of cases) (Table 3). According to Humbert and Dupond's classification, 18 patients (72\%) had disease that fit both criteria type 2 and type 3. An isolated type 2 was noted in 5 cases (20\%) and an isolated type 3 in 1 case (4\%). One case (4\%) was unclassifiable (Figure 2).

Treatment was based on the use of corticosteroids and Disease modifiying anti rheumatic drugs (DMARDs) and the management of specific single organ autoimmune diseases. The evolution under treatment was marked by remission of the disease in 21 cases (84\%) and relapse in 4 cases (16\%).

Table 1. Classification of humbert and dupond [1].

\begin{tabular}{cl}
\hline Types of MAS & Autoimmune diseases that constitute the types of MAS \\
\hline MAS of Type 1 & Myasthenia gravis, thymoma, polymyositis and giant cell myocarditis. \\
\hline MAS of Type 2 & $\begin{array}{l}\text { Sjogren's syndrome, rheumatoid arthritis, primary biliary cirrhosis, } \\
\text { Systemic scleroderma, and autoimmune thyroiditis. }\end{array}$ \\
\hline MAS of Type 3 & $\begin{array}{l}\text { Autoimmune thyroiditis, myasthenia and/or thymoma, Sjogren's syndrome, } \\
\text { Biermer's disease, idiopathic thrombocytopenic purpura, Addison's disease, } \\
\text { type I diabetes, vitiligo, autoimmune hemolytic anemia, systemic lupus. }\end{array}$ \\
\hline
\end{tabular}


Table 2. Mode of discovery of MAS.

\begin{tabular}{ccc}
\hline $\begin{array}{c}\text { Autoimmune diseases that have permitted } \\
\text { to the discovery of MAS }\end{array}$ & Number of cases & Percentage (\%) \\
\hline RA & Connective tissue diseases & 44 \\
SS & 2 & 8 \\
SLE & 4 & 16 \\
SSC & 2 & 8 \\
\hline Single organ specific autoimmune diseases & \\
\hline Graves' disease & 3 & 12 \\
Hashimoto's disease & 1 & 4 \\
Pernicious anemia & 1 & 4 \\
Vitiligo & 1 & 4 \\
Total & 25 & 100 \\
\hline
\end{tabular}

RA: rheumatoïd arthritis; SS: Sjogren's syndrome; SLE: Systemic lupus erythematosus; SSC: Systemic scleroderma.

Table 3. The different associations of autoimmune diseases.

\begin{tabular}{ccc}
\hline The different multiple autoimmune syndromes & Number of cases & Percentage (\%) \\
\hline RA + SS + Vitiligo & 1 & 4 \\
RA + SS + Pernicious anemia & 1 & 4 \\
RA + SS + SLE & 3 & 12 \\
RA + SS + Graves' disease & 5 & 20 \\
RA + SSC + Pernicious anemia & 1 & 4 \\
RA + SSC + SLE & 1 & 4 \\
RA + SS + Graves' disease + Vitiligo & 1 & 4 \\
RA + SS + Polymyositis + SSC & 1 & 4 \\
RA + SS + SLE + Vitiligo & 1 & 4 \\
SS + SSC + SLE & 7 & 28 \\
SS + SSC + Vitiligo & 1 & 4 \\
SS + SSC + Hashimoto's disease & 1 & 4 \\
SS + Polymyositis + Vitiligo & 1 & 4 \\
Total & 25 & 100 \\
\hline
\end{tabular}

RA: rheumatoïd arthritis; SS: Sjogren's syndrome; SLE: Systemic lupus erythematosus; SSC: Systemic scleroderma.

\section{Discussion}

We described in the present study the epidemiological, diagnostic and treatment characteristics of 25 patients with MAS. MAS were an entity rarely described in the African literature. In North Africa [14]-[20], as in Africa South of the Sahara [12] [13], the entity is reported as an isolated observation or in short series 


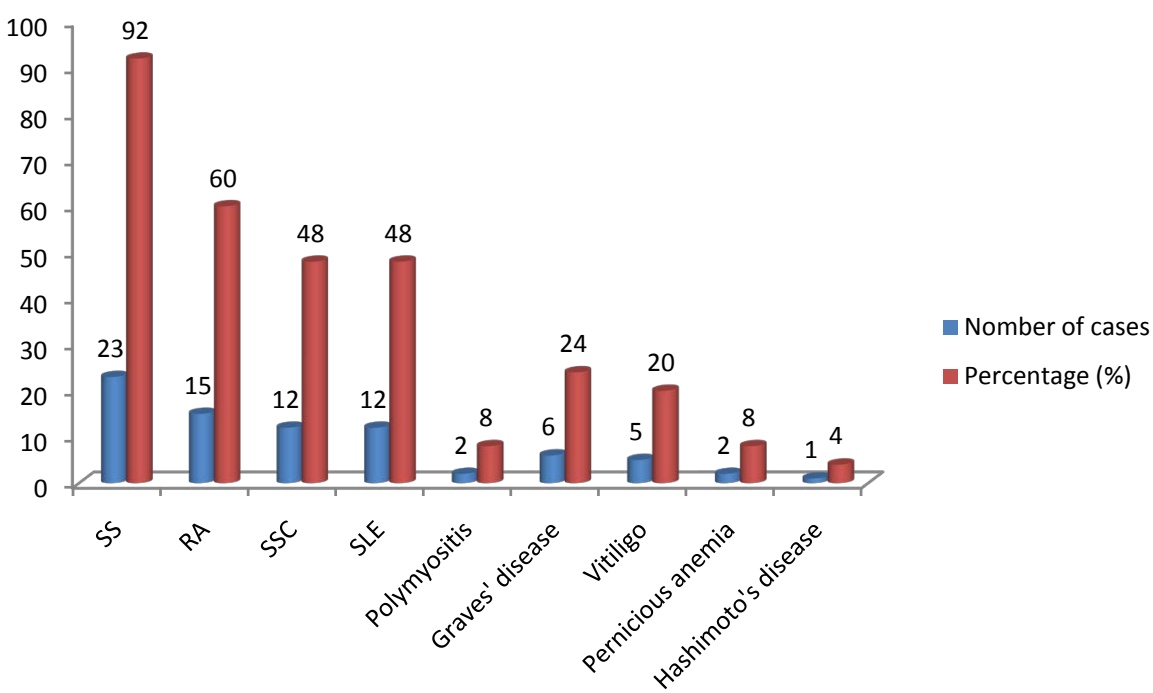

Figure 1. Autoimmune diseases that constitute the MAS in our study. RA: rheumatoï arthritis; SS: Sjogren's syndrome; SLE: Systemic lupus erythematosus; SSC: Systemic scleroderma.

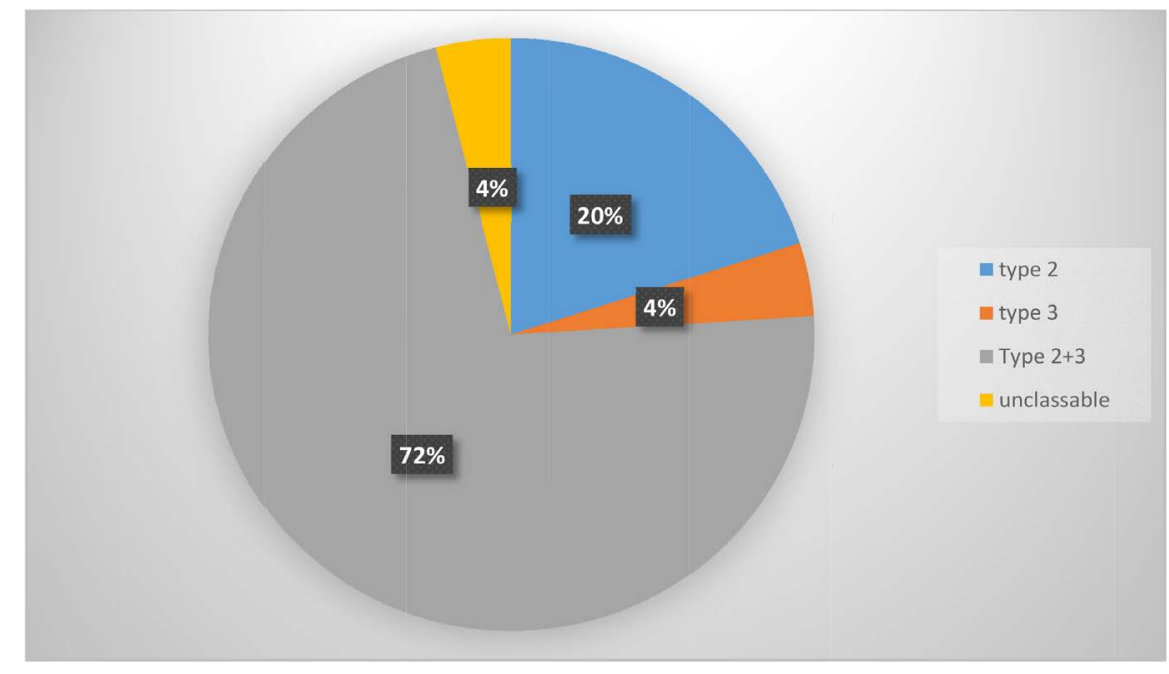

Figure 2. Distribution of MAS according to Humbert and Dupond classification in our study.

[14] [15] [16] [17]. Kane et al. reported also in a multicentric study about 726 patients with systemic diseases in Dakar, only 7 cases of MAS. However, the (MAS) was likely to be underestimated in sub-Saharan Africa, as there is a considerable increase in the incidence of autoimmune diseases in those regions [21] [22] [23] [24]. This entity should be considered, because there is evidence that 25 to 30 percent of autoimmune disease are thought to progress to polyautoimmunity [2]. This was the situation in our study where, where association of two or more autoimmune diseases was found in $25.18 \%$ of cases.

MAS is more described in the Western literature, nevertherless, it is less described than some isolated autoimmune diseases, such as RA, SLE, SS, autoimmune thyroiditis. In a recent review of the literature, Manuel $\mathrm{O}$, et al. showed 
that MAS of type I affected 1 case in 2 to 3 million newborns. Its prevalence in the general population is estimated at 1/90,000 in Norway, 1/130,000 in Ireland [25]. MAS is thought to be higher in Sardinians and Iranian Jews with a prevalence of 1/14,000 and 1/9000, respectively [25]. The classical female predominance is found in our study [13] [14] [26] [27]. The female sex seems to be a risk factor for polyautoimmunity [2] [27]. The age of onset of the disease varies according to the studies [14] [28]. However, the peak is in the third and fourth decade [14] [28] [29] [30] [31]. The mean age among our patients was also in accordance to the literature data.

A context of family autoimmunity was found in $84 \%$ of cases. It is now known that family history of autoimmunity, described by several authors [4] [14] [15] [32] [33] [34], is a risk factor for MAS [2] [9] [27]. Thus, familial aggregation of autoimmune diseases could be suggested that there is a common genetic basis for autoimmunity. The search for susceptibility genes has not been performed in our patients. However, HLA Antigengeno typing performed in Senegal confirms the association of SS and RA with HLA-DR10 [35]. In Caucasians, there is an association between MAS and haplotypes: DR3, B8-DR3 and A1-B8-DR3, DR3-DQ2, DR4-DQ8 [36] [37]. HLA DR3 could thus be an immunogenetic thread in the association of different autoimmune diseases within a MAS [38]. The association between autoimmune diseases and non-HLA gene polymorphism has also been reported. Thus the PTPN22, STAT4 and PDCD1 genes have been implicated. [38]. A mutation in the AIRE gene located on chromosome 21 has been described in multiple autoimmune syndrome type I [25]. It has autosomal recessive transmission. The AIRE gene is expressed in thymic bone marrow cells and codes for a DNA binding protein called an autoimmune regulator. This protein helps regulate the thymic expression of various tissue-specific antigens leading to the elimination of auto-reactive $\mathrm{T}$ cells. In its absence, self-reactive cells escape negative selection and are released into the circulation [25] [39].

In addition to genetic factors, epigenetic factors, including physical, infectious, endocrine and even psychological factors acting in concert, contribute to the determinism of autoimmune diseases and thus to MAS [40] [41] [42].

The evaluation of all these factors has not been carried out in our patients, however they all came from countries with strong sunshine and no notion of smoking has been found. The average time to diagnosis in our study was 2.52 years. This indicates efforts to be made in terms of popularization these pathologies for early detection.

The most frequent autoimmune diseases in our study was SS (92\%), followed by RA $(60 \%)$, in the group of connective tissue diseases and Graves's disease (24\%), in single organ specific autoimmune diseases. The association between SS, SLE and SSC was most common in $28 \%$ of cases. It was followed by the association between RA, SS and Graves' disease (20\% of cases). Indeed, SS and Graves' disease are the autoimmune diseases most frequently associated with polyautoimmunity [2] [43]. Anaya, in her systematic review on polyautoimmunity during SS, found that the autoimmune diseases that were frequently associated with it, 
were autoimmune thyroiditis, RA, SLE, SSC. These results are thus similar to those observed in our study [9].

The majority of MAS in our study involved 3 autoimmune diseases. We found only 3 cases with an association of 4 autoimmune diseases. In the series of the literature, the association of 4 autoimmune diseases in a MAS has been described. The presence of 5 autoimmune diseases in a MAS is an exceptional situation [14] [29] [30] [32] [43]. MAS fitted both Humbert and Dupont types 2 and 3 in 18 cases (72\%), type 2 in 5 cases (20\%) and type 3 in 1 case (4\%). One patient had an unclassifiable form (4\%). Numerous studies have reported cases of MAS that are unclassified according to the Humbert and Dupond's classification [27] [29]. It is therefore necessary to develop a new classification that includes these new associations.

The favourable evolution under DMARDS in $84 \%$ of the cases shows an efficacity of these drugs in spite of the complex nature of these diseases. The uncontrolled cases were eligible for bio-drugs, which are not available in our regions.

The main limitation of our study was the small sample size that does not allow us to predict a real statistical trend. It would be necessary to conduct a prospective and multicentric study on large sample to better understand this entity.

\section{Conclusion}

MAS constitute $5.66 \%$ of all the autoimmune diseases in our study. They predominate in young women with a mean age of 42.4 years. They are associated with both connective tissue diseases and single organ specific autoimmune diseases. Not all entities are classifiable by the Humbert and Dupond's classification. The evolution under treatment is marked by remission in $84 \%$ of cases. The study has to be continued in an expanded prospective study.

\section{Consent for Publication}

Written informed consent for publication was obtained from the patients.

\section{Conflicts of Interest}

The authors declare no conflicts of interest regarding the publication of this paper.

\section{References}

[1] Humbert, Ph. and Dupond, J.L. (1988) Multiples Autoimmunediseases. Annales de Médecine Interne, 139, 159-168.

[2] Anaya, J.-M. (2017) The Autoimmune Tautology. A Summary of Evidence. Joint Bone Spine, 84, 251-253. https://doi.org/10.1016/j.jbspin.2016.11.012

[3] Deretzi, G., Kountouras, J., Polyzos, S.A., Koutlas, E., Pelidou, S.-H., Xeromerisiou, G., Zavos, C. and Tsiptsios, I. (2015) Polyautoimmunity in a Greek Cohort of Multiple Sclerosis. Acta Neurologica Scandinavica, 131, 225-230. https://doi.org/10.1111/ane.12308

[4] Kechida, M., Klii, R., Hammami, S. and Khochtali, I. (2016) Multiple Autoimmune 
Syndrome in a Department of Internal Medicine. La Revue de Médecine Interne, 37, A246. https://doi.org/10.1016/j.revmed.2016.10.338

[5] Forsea, A.M., Mihai, C., Predescu, T., Tudose, I., Margaritescu, I. and Giurcaneanu, C. (2017) Polyglandular Autoimmune Syndrome Associated with Multiple Autoimmune Conditions and Atopic Dermatitis-An Unusual Manifestation of a Polyautoimmunity Phenotype. Acta Endocrinologica (Buchar), 13, 106-110. https://doi.org/10.4183/aeb.2017.106

[6] Samanta, D., Ramakrishnaiah, R., Crary, S.E., Sukumaran, S. and Burrow, T.A. (2019) Multiple Autoimmune Disorders in Aicardi-Goutières Syndrome. Pediatric Neurology, 96, 37-39. https://doi.org/10.1016/j.pediatrneurol.2019.01.017

[7] Niknezhad, N., Ghalamkarpour, F., Niknejad, N. and Asadi-Kani, Z. (2018) Coexistence of Mucous Membrane Pemphigoid, Vitiligo, and Hypothyroidism: A Second Report of a New Multiple Autoimmune Syndrome. Dermatologic Therapy, 31, e12717. https://doi.org/10.1111/dth.12717

[8] Sereshki, M.M.A., Almasi, S., Beham, B. and Semnani, F. (2019) Autoimmune Haemolytic Anaemia and Multiple Autoimmune Syndrome. European Journal of Case Reports in Internal Medicine, 6, Article ID: 00111.

[9] Anaya, J.-M., Rojas-Villarraga, A., Mantilla, R.D., Arcos-Burgos, M. and Sarmiento-Monroy, J.C. (2016) Polyautoimmunity in Sjögren Syndrome. Rheumatic Disease Clinics of North America, 42, 457-472. https://doi.org/10.1016/j.rdc.2016.03.005

[10] Horimoto, A.M.C., do Carmo Silveira, A.F. and da Costa, I.P. (2016) Familial Autoimmunity and Polyautoimmunity in 60 Brazilian Midwest Patients with Systemic Sclerosis. Revista Brasileira de Reumatologia (English Edition), 56, 314-322. https://doi.org/10.1016/j.rbre.2016.01.003

[11] Setoue, D.N., Pitta, A.C., Fiorot, F.J., Nastri, M.M., Novaka, G.V., Molinari, B.C., Oliveira, J.C., et al. (2018) Symptomatic Polyautoimmunity at Diagnosis of 1463 Childhood-Onset Lupus: A Brazilian Multicenter Study. Autoimmunity Reviews, 17, 836-839. https://doi.org/10.1016/j.autrev.2018.03.009

[12] Talabi, O.A., Owolabi, M.O. and Osotimehin, B.O. (2003) Autoimmune Diseases in a Nigerian Woman-A Case Report. West African Journal of Medicine, 22, 361-363. https://doi.org/10.4314/wajm.v22i4.28067

[13] Diallo, S., Ka, M.M., Pouye, A., Kane, A., Ndongo, S., Leye, A. and Diop, T.M. (2001) Multiple Autoimmune Syndromes in Black Africans in Senegal: Study of 69 Observations. Revue du Rhumatisme, 68, 1009-1010.

[14] Maamouri, N., Kchir, H., Mebazza, A., Nacef, I.B., Belkahla, N., et al. (2010) Liver Damage in Multiple Autoimmune Syndrome: About 15 Cases. La Revue de Médecine Interne, 31, S167. https://doi.org/10.1016/j.revmed.2010.03.278

[15] Ach, M.T., Akkari, I., Maaroufi, A., Kacem, M., Chaieb, M. and Ach, K. (2016) Biermer Anemia and Autoimmune Diseases: About 28 Cases. Annales dEndocrinologie, 77, 375. https://doi.org/10.1016/j.ando.2016.07.402

[16] Hannachi, R., Belkacem, I. and Boudiba, A. (2018) Type 1 Diabetes in Multiple Autoimmune Syndrome: About One Case. Annales d Endocrinologie, 79, 499-500. https://doi.org/10.1016/j.ando.2018.06.1012

[17] Ben Salah, R., Chebbi, D., Kacem, F.H., Chabchoub, I., Abid, M., Frikha, F. and Bahloul, Z. (2018) Thyroid Disease and Syndrome Multiple Autoimmune Syndrome: A Study of 13 Cases. Annales d Endocrinologie, 79, 355. https://doi.org/10.1016/j.ando.2018.06.498

[18] Bel Feki, N., Ben Ghorbel, I., Ben Salem, T., Hamzaoui, A., Lamloum, M., Sellami, M. and Houman, H. (2014) Multiple Autoimmune Syndrome: When One Patholo- 
gy Hides Another. About One Case. Annales d Endocrinologie, 75, 509-510. https://doi.org/10.1016/j.ando.2014.07.818

[19] Allam, M.M. and Elzawawy, H.T.H. (2018) Induction of Remission in Autoimmune Polyglandular Syndrome Type Three (APS III): An Old Drug with New Perspectives. Clinical Case Reports, 6, 2178-2184. https://doi.org/10.1002/ccr3.1827

[20] Amraoui, N., Meziane, M., Lahlou, A., Gallouj, S., Rabhi, S., Bono, W. and Mernissi, F. (2015) Multiple Autoimmune Syndrome with Vitiligo, Autoimmune Thrombocytopenia and Autoimmune Dermoepidermal Bullous Dermatosis. International Journal of Dermatology and Clinical Research, 1, 11-13. https://doi.org/10.17352/2455-8605.000005

[21] Niasse, M., Kane, B.S., Ndiaye, A.B., Ndao, A.C., Djiba, B., Fall, S., Diack, N.D., et al. (2017) Severity of the Rheumatoid Arthritis in Sub-Saharan Africa: Study of 403 Senegalese Observations. Open Journal of Internal Medicine, 7, 151-159. https://doi.org/10.4236/ojim.2017.74016

[22] Kane, B.S., Niasse, M., Ndiaye, A.A., Ndao, A.C., Djiba, B., Diack, N.D., Fall, B.C., et al. (2018) Systemic Diseases in Dakar (Senegal): Spectrum, Epidemiological Aspect and Diagnostic Time-Limit. Open Journal of Internal Medicine, 8, 196-206. https://doi.org/10.4236/ojim.2018.83019

[23] Mijiyawa, M., Amanga, K., Oniankitan, O.I., Pitch, P. and Tchangdi-Walla, K. (1999) The Connective Tissue Diseases in Hospital Consultation in Lomé (Togo). La Revue de Médecine Interne, 20, 13-17. https://doi.org/10.1016/S0248-8663(99)83004-5

[24] Kombaté, K., Saka, B., Teclessou, J.N., Matacloe, H., Akakpo, S.A., Mouhari-Touré, A. and Pitché, P. (2016) The Connective Tissue Diseases in Hospitals in Lomé. Annales de Dermatologie et de Vénéréologie, 143, S51. https://doi.org/10.1016/S0151-9638(16)30219-8

[25] Bello, M.O. and Garla, V.V. (2019) Polyglandular Autoimmune Syndrome Type I. StatPearls Publishing, Treasure Island, FL.

[26] Lazarus, M.N. and Isenberg, D.A. (2005) Development of Additional Autoimmune Diseases in a Population of Patients with Primary Sjögren's Syndrome. Annals of Rheumatic Diseases, 64, 1062-1064. https://doi.org/10.1136/ard.2004.029066

[27] Matusiewicz, A., Stróżyńska Byrska, J. and Olesińska, M. (2018) Polyautoimmunity in Rheumatological Conditions. International Journal of Rheumatic Diseases, 22, 386-391. https://doi.org/10.1111/1756-185X.13454

[28] Kahaly, G.J. (2012) Polyglandularautoimmune Syndrome Type II. La Presse Médicale, 41, e663-e670. https://doi.org/10.1016/j.lpm.2012.09.011

[29] Cherif, Y., Ben Salah, R., Frikha, F., Dammak, C., Jallouli, M., Snoussi, M., Garbaa, S., et al. (2014) Multiple Autoimmune Syndrome: About 17 Observations. La Revue de Médecine Interne, 35, A142. https://doi.org/10.1016/j.revmed.2014.10.242

[30] Michaud, M., Bonis, C., Conor, C., Inchauspe, A., Broussaud, S., Couteau, C., et al. (2012) Multiple Autoimmune Syndrome: About a Series of Eight Cases. La Revue de Médecine Interne, 33, A108-A109. https://doi.org/10.1016/j.revmed.2012.10.169

[31] Zemmour, D., Ouadahi, N., Hakem, D., Kessal, F., Bensalah, D., Boudjelida, A., et al. (2002) Multiple Autoimmune Syndromes: Clinical Aspects. La Revue de Médecine Interne, 23, 626s. https://doi.org/10.1016/S0248-8663(02)80546-X

[32] Anaya, J.-M., Castiblanco, M., Rojas-Villarraga, A., Pineda-Tamayo, R., Levy, R.A., Gómez-Puerta, J., et al. (2012) The Multiple Autoimmune Syndromes. A Clue for the Autoimmune Tautology. Clinical Review in Allergy and Immunology, 43, 256-264. https://doi.org/10.1007/s12016-012-8317-z 
[33] Rojas-Villarraga, A., Toro, C.-E., Espinosa, G., Rodríguez-Velosa, Y., Duarte-Rey, C., Mantilla, R.D., et al. (2010) Factors Influencing Polyautoimmunity in Systemic Lupus Erythematosus. Autoimmunity Reviews, 9, 229-232. https://doi.org/10.1016/j.autrev.2009.10.001

[34] Zantour, B., Sfar, M.H., Alaya, W., Chebbi, W. and Chouchene, L. (2010)Type 1 Diabetes Mellitus and Multiple Autoimmune Syndromes: About 11 Observations. Diabetes \& Metabolism, 36, A63. https://doi.org/10.1016/S1262-3636(10)70249-4

[35] Dieye, A., Diallo, S., Diatta, M., Ndiaye, R., Bao, O. and Sarthou, J.L. (1997) Identification of HLA-DR Alleles of Susceptibility to Rheumatoid Arthritis. Dakar Medical, 42, 111-113.

[36] Meyer, O. (1988) Contribution of Immunogenetic to the Comprehension of Multiple Autoimmune Syndromes. Annales de Médecine Interne, 139, 155-183.

[37] Klisnick, A., Schmidt, J., Dupond, J.L., Bouchou, K., Roussel, H., Thieblot, P., Vidal, E. and Aumaitre, O. (1996) HLA Phenotype and Multiple Autoimmune Syndrome. La Revue de Médecine Interne, 17, 375S. https://doi.org/10.1016/S0248-8663(97)80910-1

[38] Dieude, P. (2007) Genetic of Systemic Diseases. Revue du Rhumatisme, 74, 794-799. https://doi.org/10.1016/j.rhum.2007.07.002

[39] Anderson, M.S., Venanzi, E.S., Klein, L., Chen, Z., Berzins, S.P., Turley, S.J., von Boehmer, H., et al. (2002) Projection of an Immunological Self Shadow within the Thymus by the Aire Protein. Science, 298, 1395-1401. https://doi.org/10.1126/science.1075958

[40] Michel, M. and Nicola, L. (2008) Autoimmunes Diseases. La Revue du Praticien, 58, 909-917.

[41] Delévaux, I., Chamoux, A. and Aumaitre, O. (2013) Stress and Autoimmunity. La Revue de Médecine Interne, 3, 487-492. https://doi.org/10.1016/j.revmed.2012.10.366

[42] Lacour, J.P. (1996) Lupus et soleil. La Revue de Médecine Interne, 17, 196-199. https://doi.org/10.1016/0248-8663(96)81245-8

[43] Cojocaru, M., Cojocaru, I.M. and Silosi, I. (2010) Multiple Autoimmune Syndrome. Maedica (Buchar), 5, 132-134. 